\title{
THE ROLE OF ELECTRONIC MEDICAL RECORD IN ENHANCING RATIONAL ANTIBIOTICS PRESCRIPTION: A SYSTEMATIC REVIEW
}

\author{
Rachmat Kamaluddin, Wiku Bakti Bawono Adisasmito
}

Study Program of Hospital Administration, Faculty of Public Health, Universitas Indonesia

\begin{abstract}
Background: Antimicrobial resistance is a big problem in the world. Inappropriate use of antibiotics increases up to 36-54\% in hospitals worldwide. One of the factors that trigger antimicrobial resistance is the prescription of irrational antibiotics. In the age of increasingly developing technology, a variety of medical equipment and support also developed, including electronic medical record (EMR). This study aimed to systematically review the role of the electronic medical record in enhancing rational antibiotics prescription.

Subjects and Methods: This was a systematic review using articles obtained from 4 electronic databases, namely Proquest, EBSCO, PubMed, and Scopus. The keywords used in this study were "electronic medical record" OR "electronic health record" OR "electronic patient data" AND "hospital" AND "rational antibiotic prescribing" OR "rational antimicrobial prescribing" OR "improve antibiotic prescribing" OR "antibiotic resistance "OR "antimicrobial resistance". The data were obtained from publication in 2014 to 2019, observational study, conducted in hospital, and related to EMR. The main outcome was the change in prescription from irrational to rational use of antibiotics. The data were reviewed based on the PRISMA flow diagram.

Results: Eight of 5549 articles met the inclusion criteria and were reviewed. Four of 8 articles discussed additional information technology (IT) tools that were technologically linked to EMR. One article discussed government regulation. Two articles discussed hospital system. One articles discussed collaboration between EMR data and educational promotion. EMR provided complete information about the patient's condition, history of the disease, the pattern of therapy administration, and the cost of treatment in the hospital. However, EMR itself was not enough. Program support, additional IT system, and regulation, were needed to change the behavior of rational antibiotic prescription.

Conclusion: EMR can provide an overview of the medical record data, including patterns of antibiotics drug use. It helps the doctors to provide rational therapy easier by increase regulation, hospital system, or additional tools that support EMR in the case to reduce antimicrobial resistance.
\end{abstract}

Keywords: electronic medical record, antimicrobial resistance, improve antibiotic prescribing, hospital

\section{Correspondence:}

Rachmat Kamaluddin. Study Program of Hospital Administration, Faculty of Public Health, Universitas Indonesia. Jl. Margonda Raya, Pondok Cina, Beji, Depok 16424, West Java. Email: Rachmat.kamaluddin@ui.ac.id. Mobile: 081319420526.

\section{BACKGROUND}

Antibiotic resistance is a condition where bacteria can live and survive antibiotic administration. The term antibiotic refers to a drug that specifically kills bacteria. While antimicrobial is a general term that is defined as a drug that not only kills bacteria, but fungi, viruses, parasites and other microorganisms. Based on the Centers for Disease
Control and Prevention (CDC), 2 million people experience antibiotic resistance, and 230,00o deaths due to infection each year in the United States (Fleming-Dutra et al., 2016). Among 2000-2015, global use of antibiotics increased by $65 \%$. The average antibiotic consumption per 1000 population/ day increased by $39 \%$. Penicillin is the most widely consumed antibiotic (39\% of total 
defined daily dosage (DDD), followed by cephalosporins (20\% of total DDD), quinolone and macrolide (12\% of DDD respectively). Consumption of antibiotics in low and moderate income countries (moderate) Low and Middle income countries (LMIC) are higher at $114 \%$ compared to high income countries (High income countries (HIC) by $6 \%$, but in the range of 2000-2015 both experienced an increase (Klein et al., 2018).

In 2010-2011, Fleming et al examined antibiotic prescribing at outpatient visits in the United States. There are 506 antibiotic prescriptions per 1000 population, 353 of them are rational antibiotic prescriptions. $40 \%$ of antibiotic prescriptions are in respiratory diseases such as tonsillitis, common cold, sinusitis, pharyngitis, otitis media and pneumonia are inappropriate (FlemingDutra et al., 2016).

In 2016, the CDC reported, in the United States it was estimated that $30 \%$ of antibiotic prescriptions were not as indicated (Harris et al., 2016).

Factors that cause antimicrobial resistance are from the side of patients, doctors, hospitals, state regulations and health systems, the development of vaccines and medicines, the use of antimicrobials as animal feed, and the promotion of pharmaceutical companies (World Health Organization., 2001).

Doctors as prescriber is one of the factors that play a role in the mechanism of antibiotic resistance, because doctors have the authority to administer drugs. The decision to administer antibiotics on a clinical basis is the full authority of the doctor in conducting therapy to patients. In giving antibiotics to patients, doctors can be affected by various things such as patient expectations, fear of poor clinical outcomes, promotions and gifts from pharmaceutical companies, lack of information about the patient's previous condition and updates on the latest cli- nical governance, lack of supporting examinations in diagnosing, work environment to external regulation (World Health Organization, 2001).

When accepting new patients, the doctor will assess the clinical patient, diagnose and provide therapy. Doctors need information about the patient's previous medical history to avoid drug duplication or drug interactions. The patient's information is usually contained in the hospital's medical record. A complete and integrated medical record will help the doctor in providing therapy, whereas an incomplete medical record, especially regarding basic patient health data, will make it difficult for the doctor to provide rational therapy.

\section{SUBJECTS AND METHOD \\ 1. Study Design \\ This article is a systematic review using Preferred Reporting Items for Systematic Reviews and Meta-Analysis (PRISMA). Data- base search on EBSCOhost, Pubmed, SCO- PUS, and Proquest sites. The keywords used in the search are "electronic medical records" OR "electronic medical records" OR "elec- tronic health records" OR "electronic health records" OR "electronic patient data" AND "hospitals" OR "hospitals" AND "rational antibiotic prescribing" OR "Rational anti- biotics prescribing" OR "rational antimi- crobial prescribing" OR "improve antibiotic prescribing" OR "antibiotic resistance" OR "antimicrobial resistance".}

\section{Inclusion and Exclusion Criteria}

The article sought is research published in the 2014-2019 range. The study was conducted in a hospital, because the administration of most antibiotic drugs ranging from the type, duration and dose of drugs carried out in the hospital. The results of the journals reviewed were changes in physician behavior in prescribing irrational antibiotics to be rational. This change is directly affected by 
the electronic medical record, both the electronic medical record itself is able to change it or the electronic medical record accompanied by other programs that support the rational behavior of antibiotic drug administration to occur. In conducting a review, several definetions are used to clarify the inclusion and exclusion criteria, namely:

\section{a. Rational antibiotics}

WHO defines antibiotic drugs given to patients, according to their needs, the right dosage, the correct method of administration, sufficient time periods and low costs. Called irrational if one or more of these conditions are not met (World Health Organization, 2012).

\section{b. EMR}

Electronic records containing individual health data that can be created, managed, collected and consulted by authorized physicians within the scope of a health organization (The National Alliance for Health Information Technology, 2008).

Electronic medical records are part of the electronic health record (EHR) which is a collection of several medical records of individuals in certain health organizations in certain periods. Because it contains data on patient health information electronically, EHR is included as a search keyword in the database.

Excluded articles are articles that are not research (literature review, case studies and systematic review). The place of research was not in the hospital. The results of the study were not related to the change in response to irrational antibiotic prescribing to be rational, not related to electronic medical records, articles that did not display full text, and did not speak English.

\section{RESULTS}

A total of 5549 relevant articles were obtained from 4 search database sites (SCOPUS, Proquest, Ebscohost, PubMed).
5549 articles were selected using the PRISMA guidelines and 8 articles were obtained which were in accordance with the desired information and then reviewed. 8 articles consisted of 4 articles (50\%) discussing EMR integrated with additional IT systems or already within the EMR itself, namely electronic prescribing systems, online comprehensive antibiotic stewardship program (OCASP), hospital-wide computerized antimicrobial approval system (HCAAS), and computer physician order entry (CPOE). 2 Articles (25\%) each discuss hospital programs created in the flow of drug delivery mechanisms through an antimicrobial restriction system, and visite multi-disciplinary experts to patients. 1 article (12.5\%) discusses the integration of EMR with educational promotion and 1 article (12.5\%) discusses the role of government regulation with the national action plan.

The articles reviewed were mostly conducted using cross sectional (50\%), longitudinal (25\%), retrospective observational studies (12.5\%) and cohorts (12.5\%). Research settings were mostly in the Asian region (62.5\%), Europe (25\%), and America (12.5\%). All articles have the same outcome: a rational change in the administration of antibiotic drugs, both in terms of antibiotic prescribing, and the duration of antibiotic administration.

Medical, nosocomial, and mortality costs are due to infection in the hospital. All articles also explain the function of EMR in each study, namely to provide comprehensive data on patient health data, including identity, history of illness, history of previous treatment, diagnosis and therapy provided as basic data of patients before and after intervention.

\section{The integrated EMR IT system}

Most of the articles reviewed discuss IT systems attached to EMR or additional IT systems that do not yet exist in the EMR feature. 
As technology develops, EMR is increasingly developing, starting from displaying only patient health data, to extending its function to other supporting units in hospitals, such as pharmacy, with electronic prescription features.

Allan et al. (2016) investigated electronic prescribing with CareVue brand EMR from Phillips, through documentation of antibiotic initiation and termination time, where there was an increase in good monitoring of drug administration at the time of initiation $\left(\chi^{2}(4)=39.69, p<0.0001\right)$ and stoppage time $\left(\chi^{2}(4)=42.10, p<0.0001\right)$ compared before using electronic prescribing and post-socialization procedures for the use of antibiotics.

CPOE is a computerized doctor's instruction to medical personnel or other units in the role of providing therapy to patients. With the help of consensus on the administration of vancomycin antibiotics, the use of CPOE resulted in an increase of $21.9 \%$ (p $<0.05$ ) in doses corresponding to $67.4 \%$ (254/377) post-CPOE vancomycin doses compared to $45.5 \%(100 / 220)$ in pre-CPOE doses.

In critically ill patients, there was a $16.3 \%$ increase in doses corresponding to $44.7 \%(38 / 85)$ in the post-CPOE group compared to $28.4 \%(19 / 67)$ in the pre-CPOE group (Hall et al., 2015). Ling Chen et al. (2018) investigated the use of EMR's integrated comprehensive antibiotic stewardship program (OCASP). OCASP has been implemented in Taiwan since 2005.

In summary, OCASP works when doctors want to prescribe certain antibiotics, so they must be approved by infectious disease specialists via online or mobile short message service. Full patient data and clinical conditions are submitted to the specialist doctor. If approved, the drug may be given to the patient, otherwise if it is not approved then must replace or stop the antibiotic.
The overall trend for antimicrobial use increased significantly before OCASP application ( $p<0.001$ ), but decreased significantly after implementation $(\mathrm{p}<\mathrm{0.01})$. The duration of administration of all antibiotic classes was significantly shorter $(\mathrm{p}<0.001)$ and the incidence of Hospital Acquired Infection was significantly lower $(\mathrm{p}<0.001)$ after implementation (Chen et al., 2018).

Similar to procedures such as OCASP, the hospital-wide computerized antimicrobial approval system (HCAAS) is an intranetbased application that also reduces antimicrobial use, hospital-related pneumonia events, and hospital mortality rates (crude death related to sepsis, and overall death related to infection).

In this study, HCAAS was combined with an infection specialist, which compared to a period of 3 , namely when there were no specialist infectious doctors, there were part timer infectious specialists and full timer infectious specialists. The presence of a full timer infection specialist has a significant effect on the use of antibiotics (Huang et al., 2018).

\section{A combination of EMR and hospital system}

In 2 articles discussing hospital systems within the framework of antimicrobial resistance programs, EMR plays a role in providing patient data namely demographic and clinical data, including length of stay, specialized care (medical or surgical) under the patient during treatment, the presence of clinical pneumonia, the use of antimicrobials, and duration of treatment. These EMR data were compared before and after the intervention.

Wanla et al. (2017) studied the antimicrobial restriction system at Lamphun hospital. In brief, the restriction system is that the doctor prescribes antibiotics for a maximum of 3 days and fills in the form submitted to the pharmacy, then the pharmacy evaluates the antibiotics given starting from the 
dose, the route of administration to the impact of the dose to the kidney and collaborates with the laboratory to conduct culture.

For 3 days, internists (not the patient's physician) were appointed as evaluators of antibiotic use, visited patients and examined the effects of antibiotics. After the culture results are released, the pharmacy reports to the patient's physician about the results of antibiotic administration, whether they are still sensitive or resistant to infection.

The accuracy of the prescription was higher after using antimicrobial restrictions (55.0\%) than before using the antimicrobial restriction system $(38.3 \% ; p=0.001)$. The incidence rate of nosocomial infections caused by Enterobacteriaceae resistance to ertapenem before and after interventions to limit antimicrobial therapy was found to decrease from 4.80 to 0.95 infections per 1,000 patient days $(\mathrm{p}=1.00)$.

Expenditures for carbapenem in the average value of Baht per patient were found to have decreased by $36.33 \%$ after using an antimicrobial restriction system when compared to before using an antimicrobial restriction system $(\mathrm{p}=0.001)$ (Wanla et al., 2017).

Tiszai-Szucs et al. (2018) investigated the involvement of multiple disciplines in the administration of therapy to reduce the duration of antibiotic use. Multi disciplines involved are clinical pharmacy, clinical microbiology, and intensivis. After the three visited the patient and made an assessment, a recommendation was issued as input to the patient's physician in charge. The amount of prescription and duration of vancomycin and co-amoxiclav therapy decreased compared without the involvement of the 3 disciplines (Tiszai-Szucs et al., 2018).

\section{A combination of EMR and promo- tional education}

Nasr et al. (2019) evaluate the administration of antibiotics in cancer patients who have infections with PDSA tools (Plan, Do, Study, Act), then conduct promotional education to multidisciplinary experts (doctors and pharmacists) about antibiotic management programs continuously and assesses problems experienced when do rational antibiotic therapy in patients.

The EMR serves to provide complete clinical history data of the patient before education and compared after education. From the identification of problems, one of which relates to EMR is some incomplete patient data both identification and clinical and therapeutic history. Incomplete EMR influences patient therapy. The results of educational research on the management of rational antibiotic administration to the multidisciplinary sciences make the difference more rational than before (Nasr et al., 2019).

\section{A combination of EMR and govern- ment regulation}

In July 2011, the Chinese government implemented a National Action Plan in order to reduce antibiotic misuse in the community. The Action Plan determines:

1. The hospital director must be responsible for patient outcomes and the cost-effectiveness of using antibiotics;

2. The prescription evaluation system must be enforced with real disciplinary action against violations

3. The department of infectious diseases and the microbiology department must be upheld to work in collaboration with clinical pharmacists and other professsionals with routine responsibilities for infection control

4. Policy on the use of structured antibiotics (unlimited, limited and very limited) must be established and doctors must be trained and accredited before prescribing antibiotics.

Unlimited antibiotics (first line) refer to antibiotics with proven efficacy, relatively low prices and little effect on 
antibiotic resistance; limited antibiotics (second line) refer to those who have proven efficacy, relatively high prices and a greater effect on antibiotic resistance; and very limited antibiotics refer to those who have known side effects. Crosssectional analysis showed that antibiotic prescribing was reduced to $35.3 \%$ and 12.9\% in inpatient and outpatient settings, the intensity of antibiotic consumption was reduced to 35.9 DDD / 100 bed-days, the patient's cost of antibiotics was significantly reduced, and the duration of perioperative antibiotic treatment received by surgical patients who underwent 4 types of clean procedures (thyroidectomy, breast surgery, hernias, or orthopedic procedures) decreased to less than 24 hours during the assessment period (Bao et al., 2015).

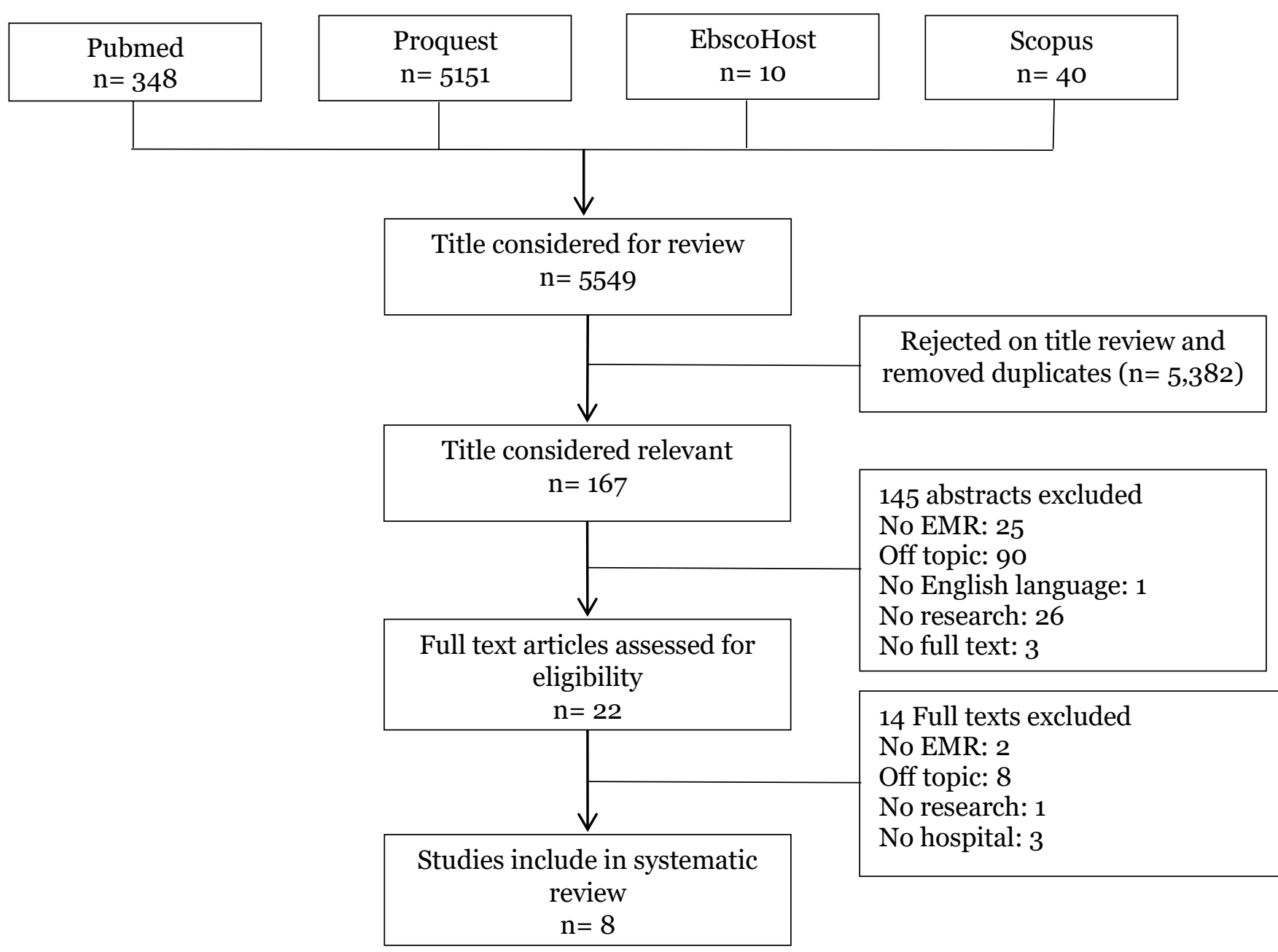

Figure 1. PRISMA flow diagram 
Table 1. Articles reviewed

\begin{tabular}{|c|c|c|c|c|c|}
\hline No & Title & Location & Instrument & Method & Results \\
\hline 1 & $\begin{array}{l}\text { The use of daily } \\
\text { electronic } \\
\text { prompts to help } \\
\text { improve } \\
\text { antimicrobial } \\
\text { stewardship in a } \\
\text { critical care unit } \\
\text { (Allan et al., } \\
\text { 2016) }\end{array}$ & The UK & $\begin{array}{l}\text { EMR + electronic } \\
\text { prescribing } \\
\text { system }\end{array}$ & Cross sectional & $\begin{array}{l}\text { Electronic prescribing } \\
\text { system (EPS) integrated } \\
\text { into the EMR helps } \\
\text { physicians provide } \\
\text { rational antibiotics, } \\
\text { especially in terms of } \\
\text { monitoring the duration } \\
\text { of antibiotic } \\
\text { administration in } \\
\text { patients when starting } \\
\text { administration }\left(\chi^{2}(4)=\right. \\
39.69, P<0.0001) \text { and } \\
\text { ending drug } \\
\text { administration }\left(\chi^{2}(4)=\right. \\
42.10, P<0.0001) .\end{array}$ \\
\hline 2 & $\begin{array}{l}\text { Practice } \\
\text { implications of an } \\
\text { antimicrobial } \\
\text { stewardship } \\
\text { intervention in a } \\
\text { tertiary care } \\
\text { teaching hospital, } \\
\text { Qatar (Nasr et al., } \\
\text { 2019) }\end{array}$ & Qatar & $\begin{array}{l}\text { EMR + } \\
\text { promotion of } \\
\text { education }+ \\
\text { effective } \\
\text { communication }\end{array}$ & Cross sectional & $\begin{array}{l}\text { In the last } 3 \text { years, } \\
\text { changes in the medical } \\
\text { record system to } \\
\text { electronic, effective } \\
\text { communication, } \\
\text { continuous education } \\
\text { promotion, complete } \\
\text { medical record } \\
\text { documentation have led } \\
\text { to a slight increase in } \\
\text { the prescription of } \\
\text { rational antibiotics } \\
\text { compared to previous } \\
\text { years }\end{array}$ \\
\hline 3 & $\begin{array}{l}\text { Effects of } \\
\text { implementation } \\
\text { of an online } \\
\text { comprehensive } \\
\text { antimicrobial- } \\
\text { stewardship } \\
\text { program in ICUs: } \\
\text { A longitudinal } \\
\text { study (Chen et al., } \\
\text { 2018) }\end{array}$ & Taiwan & $\begin{array}{l}\text { EMR + OCASP } \\
\text { linked-EMR } \\
\text { (online } \\
\text { comprehensive } \\
\text { antibiotic } \\
\text { stewardship } \\
\text { program) }\end{array}$ & Longitudinal & $\begin{array}{l}\text { Antibiotic use decreased } \\
\text { after OCASP use (p } \\
<0.01) \text { compared to } \\
\text { before OCASP (p } \\
<0.001) \text {. In addition, } \\
\text { the duration of } \\
\text { antibiotic use decreased } \\
\text { ( } \mathrm{p}<0.001) \text { and the } \\
\text { incidence of HAI } \\
\text { decreased (p < }<0.001) \\
\text { after OCASP use. }\end{array}$ \\
\hline 4 & $\begin{array}{l}\text { Implementation } \\
\text { and outcomes of } \\
\text { hospital- wide } \\
\text { computerized } \\
\text { antimicrobial } \\
\text { approval system } \\
\text { and on-the-spot } \\
\text { education in a } \\
\text { traumatic } \\
\text { intensive care } \\
\text { unit in Taiwan } \\
\text { (Huang et al., } \\
\text { 2018) }\end{array}$ & Taiwan & $\begin{array}{l}\text { EMR + HCAAS } \\
\text { linked-EMR } \\
\text { (hospital-wide } \\
\text { computerized } \\
\text { antimicrobial } \\
\text { approval system) } \\
\text { + dokter spesialis } \\
\text { infeksi }\end{array}$ & $\begin{array}{l}\text { Restrospective } \\
\text { observasional }\end{array}$ & $\begin{array}{l}\text { The combination of } \\
\text { HCAAS implementation } \\
\text { and the presence of full- } \\
\text { time infection specialist } \\
\text { doctors reduces the use } \\
\text { of antibiotics, the } \\
\text { incidence of hospital } \\
\text { acquired pneumonia, } \\
\text { medical costs, and } \\
\text { mortality due to } \\
\text { infection }\end{array}$ \\
\hline
\end{tabular}




\begin{tabular}{|c|c|c|c|c|c|}
\hline 5 & $\begin{array}{l}\text { Effects of an } \\
\text { antimicrobial } \\
\text { restriction system } \\
\text { on appropriate } \\
\text { carbapenem use } \\
\text { in a hospital } \\
\text { without infectious } \\
\text { diseases } \\
\text { consultation } \\
\text { (Wanla et al., } \\
\text { 2017) }\end{array}$ & Thailand & $\begin{array}{l}\text { EMR + } \\
\text { antimicrobial } \\
\text { restriction system } \\
(\mathrm{ARS})\end{array}$ & $\begin{array}{l}\text { Restropective } \\
\text { cross sectional }\end{array}$ & $\begin{array}{l}\text { Using prescribing data } \\
\text { at EMR, the accuracy of } \\
\text { the prescription was } \\
\text { higher after using } \\
\text { antimicrobial } \\
\text { restrictions ( } 55.0 \%) \\
\text { than before using the } \\
\text { antimicrobial } \\
\text { restriction system } \\
(38.3 \% ; p=0.001)\end{array}$ \\
\hline 6 & $\begin{array}{l}\text { Feasibility of } \\
\text { Antimicrobial } \\
\text { Stewardship } \\
\text { (AMS) in Critical } \\
\text { Care Settings: A } \\
\text { Multidisciplinary } \\
\text { Approach } \\
\text { Strategy (Tiszai- } \\
\text { Szucs et al., 2018) }\end{array}$ & Irlandia & $\begin{array}{l}\text { EMR + visite } \\
\text { multidisciplinary } \\
\text { science experts } \\
\text { (intensivis, } \\
\text { clinical } \\
\text { microbiology and } \\
\text { clinical } \\
\text { pharmacy) in } \\
\text { hospitalization }\end{array}$ & longitudinal & $\begin{array}{l}\text { There was a decrease in } \\
\text { the duration of } \\
\text { vancomycin and } \\
\text { coamoxiclav therapy in } \\
\text { post-visit } \\
\text { hospitalization for } \\
\text { several disciplines } \\
\text { compared to without } \\
\text { visite. }\end{array}$ \\
\hline 7 & $\begin{array}{l}\text { The effects of an } \\
\text { electronic order } \\
\text { set on } \\
\text { vancomycin } \\
\text { dosing in the ED } \\
\text { (Hall et al., 2015) }\end{array}$ & $\begin{array}{l}\text { Florida, } \\
\text { AS }\end{array}$ & $\begin{array}{l}\text { EMR + CPOE } \\
\text { (computer } \\
\text { physician order } \\
\text { entry) }\end{array}$ & $\begin{array}{l}\text { Retrospective } \\
\text { cohort }\end{array}$ & $\begin{array}{l}\text { There was an increase } \\
(21.9 \%) \text { of vancomycin } \\
\text { with a more appropriate } \\
\text { initiation dose in post- } \\
\text { CPOE ED patients } \\
\text { compared to pre-CPOE } \\
\text { and a } 16.3 \% \text { increase in } \\
\text { critical patients. }\end{array}$ \\
\hline 8 & $\begin{array}{l}\text { Significant } \\
\text { Reduction of } \\
\text { Antibiotic } \\
\text { Consumption and } \\
\text { Patients' Costs } \\
\text { after an Action } \\
\text { Plan in China, } \\
\text { 2010-2014 (Bao } \\
\text { et al., 2015) }\end{array}$ & China & $\begin{array}{l}\text { EMR + national } \\
\text { action plan } \\
\text { ministry of health }\end{array}$ & Cross sectional & $\begin{array}{l}\text { Implementation of the } \\
\text { national action plan } \\
\text { with the EMR database, } \\
\text { decreased antibiotic } \\
\text { prescribing ( } 35.3 \%) \text {, } \\
\text { decreased antibiotic } \\
\text { consumption ( } 35.9 \\
\text { DDD / 10o beds), } \\
\text { decreased treatment } \\
\text { costs. }\end{array}$ \\
\hline
\end{tabular}

\section{DISCUSSION}

The role of the EMR in the eight articles reviewed all served to provide comprehensive data on the patient's medical history, including identity, disease history, treatment history (past, current therapy, and future plans, including explaining the dose, duration of treatment, type of medication, and medical expenses), current clinical conditions, and all things needed in order to provide individual health services in the hospital.

$50 \%$ of the articles reviewed are developments from the EMR system itself, such as the e-prescribing and CPOE integrated EMR.
In addition, additional web-based applications or additional software such as OCASP and HCAAS can be made, which can support and facilitate doctors, especially in providing rational antibiotic therapy.

EHR developed from 1960-1970 along with the development of hardware capable of running EHR on computers. The development started from showing only the patient's medical history information to the billing and support system in 1992. The internet network that developed in the early 1990 s helped EMR to develop as well. 
Slowly manual medical records that were in the form of paper become computerized. The hospital even developed its flagship service, 'paperless' for all of its service activities because it was supported by EMR from the front to the back office. It's just that the use of EMR is still limited because of the expensive installation and maintenance costs, computer facilities with certain specs, data entry errors, doctors are not accustomed to using EMR. Until now, medical records are still a hybrid between electronic and manual paper use (Evans, 2016).

The medical world is a dynamic world and the uncertainty of treatment results in applying a medical science. In addition, developments in patient safety and rational treatment have led to the application of additional information besides EMR. One of the Clinical Decision Support (CDS) tools is software designed to provide direct assistance for clinical decision making, where individual patient characteristics are matched with a computerized clinical knowledge base and patientspecific assessments or recommendations are then presented to the doctor or patient for decision making.

The CDS system has been praised for its potential to reduce medical errors and improve the quality and efficiency of health care (SIM et al., 2001). Besides CDS, OCASP and HCAAS are some of the software in the future that will further develop and help the EMR function to its full potential.

In relation to the provision of rational antibiotic therapy, drug administration to patients is entirely the authority of the physiccian in charge. When prescribing drugs, the doctor with his knowledge along with background experience, pressure, and expectations from patients will influence what medication will be given. Administration of drugs cannot be carried out constantly, all clinical aspects and factors of the availability of drugs, pharmacology of drugs, patients, hospital conditions and others are seen.

Therefore, a single computerized system is currently not able to dictate doctors about what drugs should be given. EMR has been able to provide an overview of the patient's medical history and doctors with their knowledge will be helped to provide what drugs will be given to their patients.

The presence of infection specialist doctors is very important in helping to limit the use of antibiotic drugs. Then it is packaged in a flow system of drug use at the hospital and integrated into a computerized system helps to increase the rational administration of antibiotic drugs.

In this review, the combination of EMR with the drug restriction system in hospitals, government regulations, and education promotion has been proven to increase prescription of antibiotic drugs to be rational, starting from administering the initiation dose to terminating the drug, the duration of administration, the type of drug, to reducing mortality due to infection and hospital nosocomial infections.

\section{REFERENCES}

Allan PA, Newman MJ, Oehmen R, English WA (2016). The use of daily electronic prompts to help improve antimicrobial stewardship in a critical care unit. Journal of Infection Prevention, 17(4): 179184. https://doi.org/10.1177/1757177416645346

Bali A, Bali D, Iyer N, Iyer M (2011). Management of Medical Records: Facts and Figures for Surgeons. Journal of Maxillofacial and Oral Surgery, 10(3): 199-202. https://doi.org/10.1007/s12663-0110219-8

Bao L, Peng R, Wang Y, Ma R, Ren X, Meng W (2015). Significant Reduction of Antibiotic Consumption and Patients Costs after an Action Plan in China, 2010-2014. https://doi.org/10.1371/journal.pone.0118868

Chen IL, Lee CH, Su LH, Wang YCL, Liu JW 
(2018). Effects of implementation of an online comprehensive antimicrobialstewardship program in ICUs: A longitudinal study. Journal of Microbiology, Immunology and Infection, 51(1): 55-63. https://doi.org/10.1016/j.jmii.2016.06.007

Evans RS (2016). Electronic Health Records: Then,Now, and in the Future. IMIA Yearbook of Medical Informatics, 4861.

Fleming-Dutra KE, Hersh AL, Shapiro DJ, Bartoces M, Enns EA, File TM, Hicks LA, et al. (2016). Prevalence of inappropriate antibiotic prescriptions among us ambulatory care visits, 2010-2011. JAMA-Journal of the American Medical Association, 315(17): 1864-1873. https://doi.org/10.1001/jama.2016.4151

Hall AB, Montero J, Cobian J, Regan T (2015). American Journal of Emergency Medicine The effects of an electronic order set on vancomycin dosing in the ED. American Journal of Emergency Medicine, 33(1): 92-94. https://doi.org/10.1016/j.ajem.2014.09.049

Harris AM, Hicks LA, Qaseem A (2016). Appropriate antibiotic use for acute respiratory tract infection in adults: Advice for high-value care from the American college of physicians and the centers for disease control and prevention. Annals of Internal Medicine, 164(6): 425-434. https://doi.org/10.7326/M15-1840

Huang TY, Hung CH, Lai LJ, Chuang HJ, Wang CC, Lin PT, Hsu WH (2018). Implementation and outcomes of hospitalwide computerized antimicrobial approval system and on-the-spot education in a traumatic intensive care unit in Taiwan. Journal of Microbiology, Immunology and Infection, 51(5): 672-680. https://doi.org/10.1016/j.jmii.2017.10.0 04

Klein EY, Van Boeckel TP, Martinez EM, Pant S, Gandra S, Levin SA, Laxminarayan R, et al. (2018). Global increase and geographic convergence in antibiotic consumption between 2000 and 2015. Proceedings of the National Academy of Sciences of the United States of America, 115(15): E3463E3470. org/10.1073/pnas.1717295115

Nasr Z, Babiker A, Elbasheer M, Osman A, Elazzazy S, Wilby KJ (2019). Practice implications of an antimicrobial stewardship intervention in a tertiary care teaching hospital, Qatar. Eastern Mediterranean Health Journal, 25(3): 172180.

https://doi.org/10.26719/emhj.18.026

Sim I, Gorman P, Greenes RA, Haynes RB, Kaplan B, Lehmann H, Tang PC (2001). Clinical Decision Support Systems for the Practice of Evidence-based Medicine. The American Medical Informatics Association, 8(6): 527-534.

The National Alliance for Health Information Technology. (2008). Defining Key Health Information Technology Terms. Tiszai-Szucs T, Mac Sweeney C, Keaveny J, Bozza F, O Hagan Z, Martin-Loeches I (2018). Feasibility of Antimicrobial Stewardship (AMS) in Critical Care Settings: A Multidisciplinary Approach Strategy. Medical Sciences, 6(2): 40. https://doi.org/10.3390/medsci602004 o

Wanla W, Katip W, Supakul S, Apiwatnakorn $P$, Khamsarn S (2017). Effects of an antimicrobial restriction system on appropriate carbapenem use in a hospital without infectious diseases consultation. International Journal of General Medicine, 10: 443-449. https://doi.org/10.2147/IJGM.S145133

World Health Organization (2001). Global Strategy for Containment of Antimicrobial Strategy for Containment of Anti microbial Resistance. Switzerland.

World Health Organization (2012). The pursuit of responsible use of medicine: Sharing and Learning from Country Experiences. Switzerland. 